\title{
EDITORIAL
}

\section{Isolation Techniques for Hospital Patients with Viral Hepatitis: New Guidelines Premature}

In spite of the many hepatitis studies performed between World War II and the mid 1960s, there were significant gaps in our knowledge of the epidemiology of hepatitis A and hepatitis B until serologic tests for the specific diagnosis of each type became available. The discovery of Australia antigen by Blumberg and his colleagues ${ }^{1}$ in the 1960 s and the application of immune electron microscopy to the study of hepatitis $\mathrm{A}$ by Feinstone and his co-workers ${ }^{2}$ in the early 1970s led to rapid development of sensitive serologic tests for the diagnoses of hepatitis A and hepatitis B. Prior to availability of these tests, it was known that hepatitis $A$ was transmitted by the fecal-oral route and that hepatitis B could be transmitted by administration of blood and blood products. However, the duration of viremia and fecal shedding of virus in hepatitis $A$, and the possibility that hepatitis B could be spread by feces and body fluids other than blood, remained uncertain.

As a result of these uncertainties, the Center for Disease Control (CDC) $)^{3}$ had recommended that both blood precautions and enteric isolation be enforced for the duration of hospitalization of any patient with viral hepatitis. However, many studies carried out in the past decade have shed new light on the epidemiology of viral hepatitis. With new information available, Favero and his colleagues ${ }^{4}$ at the $\mathrm{CDC}$ recently recommended new guidelines for the isolation of hospital patients with viral hepatitis. The new guidelines call for fewer precautions, emphasize techniques aimed at preventing transmission by blood and blood products, and suggest that formal enteric isolation be eliminated for all types of viral hepatitis.

When possible, minimizing precautions for patients isolated for communicable diseases is desirable. Limiting the number of precautions when patients are isolated fosters better patient care, because health care personnel tend to avoid entering isolation rooms when isolation technique is cumbersome. Furthermore, eliminating unnecessary measures makes isolation more cost-effective. Thus, simplifying isolation techniques is desirable, but only when there is evidence that it is safe to do so.

It is with interpretation of epidemiologic data by Favero $e t a l .^{4}$ that I take issue. In their discussion of fecal shedding of virus in the course of hepatitis A virus infection, their interpretation of the data is that virus is shed for only a short time and in low concentrations after onset of symptoms. They cite only one study ${ }^{5}$ that is at variance with their interpretation, but there is another report that also conflicts with their conclusions. Dienstag et al. ${ }^{6}$ found viral particles in feces of 10 of 27 patients for as long as ten days after the onset of jaundice.

Favero et al. also suggest that the low concentrations of virus in stool after onset of jaundice indicate that feces of patients are less infectious after onset of symptoms. However, the reference they cite ${ }^{7}$ does not make a strong case for a direct relationship between concentration of viral particles in stool and degree of infectivity. Further, it is widely accepted that hepatitis $B$ is highly infectious, with only one or two viable viral particles needed to initiate infection. Although the hepatitis $B$ virus has a different portal of entry and differs in other significant ways from the hepatitis A virus, further studies are needed to determine how many infections particles would be needed to initiate infection with the hepatitis $A$ virus.

The contention of Favero $e t$ al. that the similar incidence of hepatitis A in health care workers and in first-time volunteer blood donors indicates that medical personnel are not at significant risk from patients hospitalized with hepatitis A can be questioned. It is possible that health care workers do not have a detectable increase in incidence of hepatitis $A$ infection because relatively few patients with hepatitis $A$ are admitted to general hospitals. Thus, a serologic survey may be an insensitive indicator for the risk of transmission of hepatitis A to medical personnel. The 
(Editorial continued)

absence of an increased risk in hemodialysis patients and associated personnel is predictable because, while blood is easily transmitted between patients and personnel, there is little contact with stool in a hemodialysis unit. The authors cite the apparent absence of transmission of hepatitis $A$ in a liver unit ${ }^{7}$ where several thousand patients were admitted over 10 years. However, observations in a highly specialized unit, where there is a high level of awareness of the danger of transmitting hepatitis and where specially trained personnel care for patients, are not applicable to a general hospital. That hepatitis $\mathrm{A}$ can be transmitted in the hospital is amply documented by Favero et al. Thus, in my opinion, the authors have failed to make their case that the feces of patients hospitalized with hepatitis A are unlikely to be important in transmitting hepatitis $A$ to health care workers.

One can also take issue with the assessment of Favero et al. of the data about the epidemiology of non-A, non-B hepatitis. First, they conclude that non-A, non-B hepatitis is transmitted in a manner similar to that of hepatitis B. However, in the absence of serologic markers for the one or more viruses that cause non-A, non- $B$ hepatitis, little is known about possible modes of transmission other than by blood, and whether virus is present in feces or other body fluids is not known. That non-A, non-B hepatitis can be spread by means other than transfusion of blood is indicated by the report of Villarejos et al. ${ }^{8}$ These authors documented non-A, non-B hepatitis in 12 patients who had not had blood transfusions and concluded that they had acquired the disease through person-to-person transmission. Whether person-to-person spread of non$A$, non-B hepatitis takes place by contact of infectious serum and secretions with skin and mucous membranes, or by the fecal-oral route, or by both routes, remains unknown. Thus, it cannot be concluded that feces from patients with non-A, non-B hepatitis pose no risk to medical personnel.

The principal concern with the new guidelines is that they eliminate formal enteric isolation for hepatitis $A$ and non-A, non-B hepatitis. As noted above, these recommendations are not supported by the currently available epidemiologic data. Even though Favero and his colleagues from the CDC have concluded that feces from patients with these two types of viral hepatitis provide a minimal risk to health care workers, they do caution that feces from these patients be handled carefully, i.e., "The usual precautions practiced with urine and feces of all other hospitalized patients should be used with those of hepatitis patients. For example, when directly handling urine and feces or containers with urine or feces, personnel should wear gloves; and urine and feces should be flushed directly down the toilet." Except for pediatric patients and uncooperative or fecally incontinent adult patients, general application of the latter measures would obviate the need for isolation for every disease for which the CDC currently recommends enteric isolation. ${ }^{3}$
However, it would not be appropriate to discontinue formal enteric isolation for any of the enteric diseases for which it is currently practiced, including hepatitis $A$ and non-A, non-B hepatitis. Although careful handling of the feces of all patients would effectively prevent transmission of enteric diseases from patient-to-patient or patient-to-personnel, many personnel will not be careful in handling stool and urine from all patients. In a large number of hospitals throughout the country, there is a shortage of nursing personnel. When the level of staffing is inadequate for the patient load, some of the first short cuts taken include elimination of good infection control practices such as hand washing between patients and the use of gloves when handling hazardous or potentially hazardous materials. Indeed, practice of good isolation technique may be all that one can hope to achieve on many nursing units. Therefore, all patients with communicable diseases should be placed on appropriate isolation, and the medical and nursing staffs should be reminded constantly that practicing good infection control techniques with these patients is particularly vital.

Patients admitted with suspected or proven hepatitis A should be placed on blood precautions and formal enteric isolation. Enteric isolation should be continued until peak levels of serum enzymes have been achieved. Most studies of fecal shedding of hepatitis A virus agree that the virus cannot be detected in feces later than the day of peak serum enzymes. ${ }^{6,7,9}$

I concur with Favero et al. that hepatitis B is not transmitted by feces, and additional evidence can be cited in support of this position. ${ }^{10-13}$ Therefore, it is appropriate that patients with suspected or proven hepatitis $B$ be cared for using only blood precautions. However, patients with grossly bloody feces should be under formal enteric isolation until the bleeding has ceased. Although enteric isolation is not indicated for most patients with hepatitis B, Favero et al. should have advised that personnel wear gloves when coming into contact with other body fluids such as saliva, bile, cerebrospinal fluid, and pleural fluid. The risk posed by contact with such fluids has not been defined but, as the authors pointed out, HBsAG has been detected in all body fluids, and the presence of hepatitis $B$ virus in saliva and semen has been documented experimentally. Another recommendation that should have been made was that glasses or goggles, as well as masks, be worn to protect the face and eyes when it is anticipated the blood may be splashed. This type of accident may occur in areas outside of the hemodialysis unit.

Any patient with suspected non-A, non-B hepatitis should be placed on blood precautions and formal enteric isolation for the duration of hospitalization. Gloves should be worn when contact with any body fluid is anticipated, and glasses or goggles and masks should be worn when blood or feces may be splashed.

The principal difference between the new guidelines and those published previously by the $\mathrm{CDC}^{3}$ is that formal enteric isolation has been eliminated for all types of hepatitis. Apparently, an enteric isolation sign (continued on page 74 ) 


\section{Vestal Medicated Lotion Soap-the Gentle Way to Reduce Cross-infection.}

Easy on your hands, tough on bacteria, Vestal Medicated Lotion Soap contains 0.5\% p-chloro-m-xylenol, a proven antibacterial agent for both Gram-positive and Gram-negative bacteria.

And equally important, its moisturizers and emollients let you wash your hands between every patient contact, yet keep them soft and gentle.

Vestal Medicated Lotion Soap, in every critical care area, could be of significant benefit to your hospital.

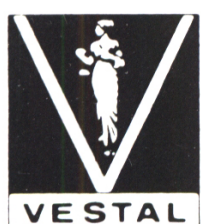

Vestal Laboratories

A Division of Chemed Corporation

The Standard of Professionals
For a free sample, just fill in and mail the coupon.

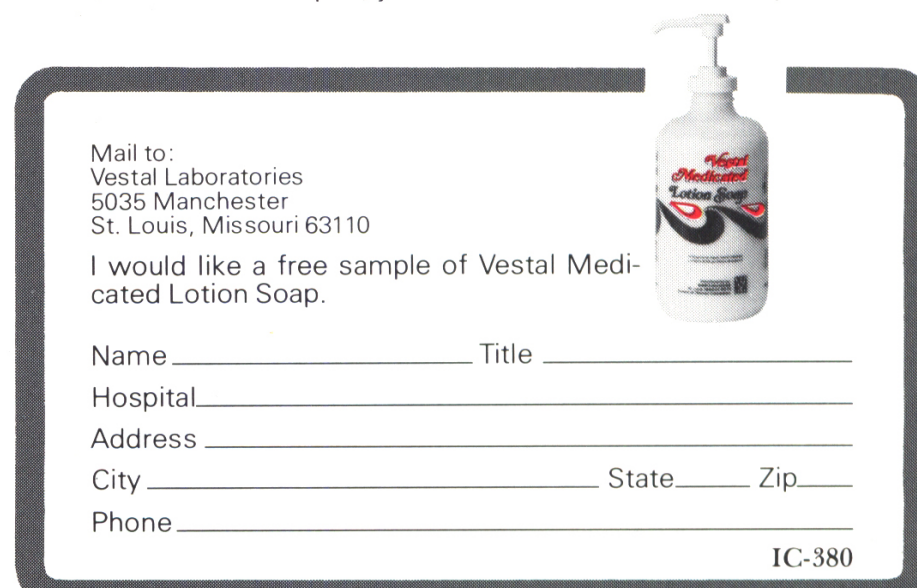


(Editorial continued)

would not be placed on the door to the patient's room, and gloves and gowns would be used only for direct contact with the patient's blood or feces. However, to avoid transmission of hepatitis by feces in the hospital, it is necessary to do more than advise personnel to follow "The usual precautions practiced with urine and feces of all other hospitalized patients...". ${ }^{4}$ If hepatitis $A$ and non-A, non-B hepatitis can be transmitted by feces in the hospital, they probably will be, just as have Escherichia coli and Salmonella.

The only way to prevent transmission in most hospitals is to isolate patients with communicable diseases appropriately, raise the staff's level of awareness of the danger posed by these patients, instruct personnel in proper technique, and monitor compliance as frequently as possible. Using formal enteric isolation with signs, gloves and gowns will accomplish two goals: (1) it will raise the level of awareness to the potential danger and (2) it will insure that, every time personnel come into contact with patients' blood and feces, their hands and clothing will be protected. Formal enteric isolation should not be abandoned for patients hospitalized with hepatitis $A$ and non- $A$, non- $B$ hepatitis unless and until the evidence against fecal transmission becomes as solid for the latter diseases as it is for hepatitis B.

\section{REFERENCES}

1. Blumberg BS, Alter HJ, Visnich SA. "New" antigen in leukemia sera. JAMA 191:541-546, 1965.

2. Feinstone SM, Kapikian AZ, Purcell RH. Hepatitis A: Detection by immune electron microscopy of a virus-like antigen associated with acute illness. Science 182:1026-1028, 1973.
3. Center for Disease Control. Isolation Techniques for Use in Hospitals. Washington, D.C., US GPO, 1975.

4. Favero MS, Maynard JE, Leger RT et al. Guidelines for the care of patients hospitalized with viral hepatitis. Ann Intern Med 91:872876,1979

5. Gust ID, Lehmann NI, Lucas CR et al. Studies on the epidemiology of hepatitis A in Melbourne. In: Vyas GN et al. (eds). Viral Hepatitis: A Contemporary Assessment of Epidemiology, Pathogenesis and Prevention. Philadelphia, The Franklin Institute Press, 1978.

6. Dienstag JL, Routenberg JA, Purcell RH et al. Foodhandlerassociated outbreak of hepatitis Type A. Ann Intern Med 83:647 $650,1975$.

7. Mosley JW. Epidemiology of HAV infection. In: Vyas GN el al. (eds): Viral Hepatitis: A Contemporary Assessment of Epidemiology, Pathogenesis and Prevention. Philadelphia, The Franklin Institute Press, 1978.

8. Villarejos VM, Visona $\mathrm{KA}$, Eduarte $\mathrm{CA}$ et al. Evidence for viral hepatitis other than Type A or Type B among persons in Costa Rica. N Engl J Med 293:1350-1352, 1975.

9. Rakela J, Mosley JW. Fecal excretion of hepatitis A virus in humans. J Infect Dis 135:933-938, 1977.

10. Havens WP Jr. Period of infectivity of patients with homologous serum jaundice and routes of infection in this disease. $J$ Exp Med 83:441-447, 1946.

11. Neefe JR, Gellis SS, Stokes J Jr. Homologous serum hepatitis and infectious (epidemic) hepatitis: Studies in volunteers bearing on immunological and other characteristics of the etiological agents. Am J Med 1:3-22, 1946.

12. Villarejos VM, Visona KA, Gutierrez A et al. Role of saliva, urine and feces in the transmission of Type B hepatitis. $N$ Engl J Med 291:1375-1378, 1974.

13. Feinman SV, Berris B, Rebane A et al. Failure to detect hepatitis B surface antigen (HBsAg) in feces of $\mathrm{HBsAg}$-positive persons. $J$ Infect Dis 140:407-410, 1979. 


\section{Pathogens don't compromise. Why should you?}

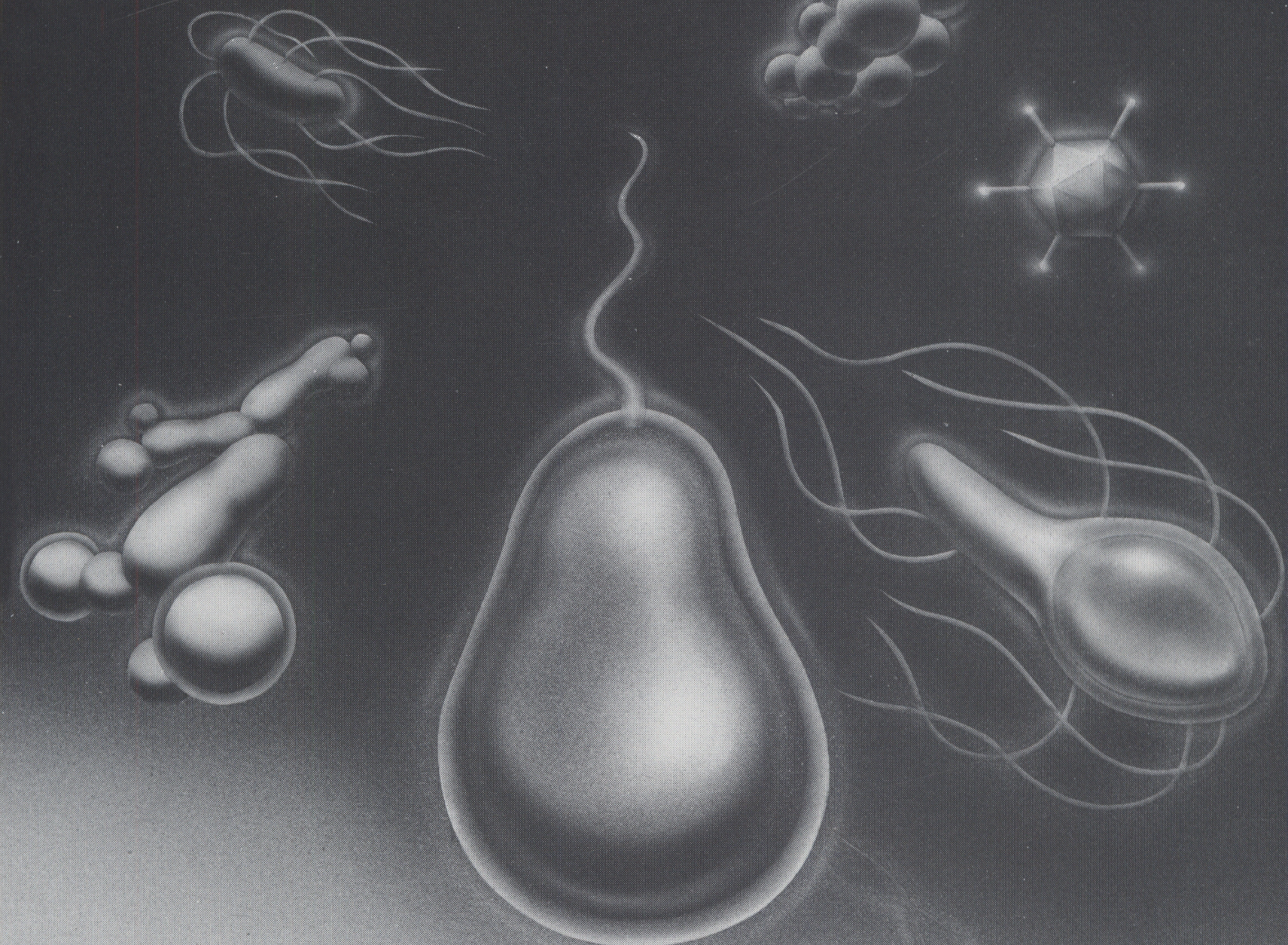

Just one pathogen species missed by an antiseptic can cause serious problems. That is why scrubbing and prepping leave no room for compromise with the quality of an antiseptic. A small difference in cost is not worth the risk.

Optimal antisepsis you can rely on

BETADINE Microbicides promptly kill gram-positive and gram-negative bacteria, fungi, viruses, protozoa and yeasts.

BETADINE Microbicides have been documented specifically by name-and in the same formulations you employ in practicein over 650 published reports encompassing thousands of clinical procedures.

BETADINE Microbicides were also chosen by NASA for disinfection procedures in Apollo splashdowns and in the Skylab mission.

\section{BETADINE Microbicides for} surgical confidence

BETADINE Surgical Scrub*-for surgical scrubbing and patient degerming. BETADINE Solution or BETADINE Aerosol Spray - for patient prepping and postoperative antisepsis on incisions.
Uncompromising antisepsis for scrubbing and prepping

BETAD|NE Surgical Scrub BETADINE Solution BETADWE 'Aerosol Spray

*In the rare instances of local irritation or sensitivity, discontinue use by the individual.

Purdue Frederick

(c) Copyright 1980, The Purdue Frederick Company/Norwalk, CT 06856 $225580 \quad \mathrm{~B} 9458$

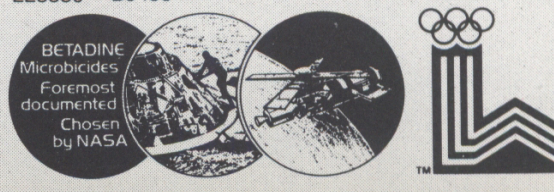

Chosen for Use at the 1980 Olympic Winter Games 